\title{
Evaluation of Anterior and Posterior Cruciate Ligament Injuries of the Knee on Magnetic Resonance Imaging: A Cross-sectional Study
}

\section{Shirish V Vaidya ${ }^{1}$, Harshal S Dhongade ${ }^{2}$, Shital M Mahajan ${ }^{3}$, Aneesh MK ${ }^{4}$}

'DMRD, DNB, Assistant Professor, Department of Radiodiagnosis, JNMC, Sawangi; ${ }^{2} M D$ Radiodiagnosis, Consultant Radiologist, Apollo Hospital, Nashik; ${ }^{3} \mathrm{MD}$, Assistant Professor, JNMC, Sawangi; ‘MD, Professor, Department of Radiodiagnosis, JMMC, Thrissur.

\section{ABSTRACT}

Background: The knee joint is complex with a variety of structures; signs/symptoms of knee injuries may all be caused by them. In the reign of Magnetic Resonance Imaging (MRI) the most landmark advances were made in knee joint imaging. A noninvasive modality, it has replaced traditional arthrography in the menisci and cruciate ligaments evaluation and has reduced both the morbidity and expense associated with the arthroscopic examination which yields negative results.

Aim: The present research was performed on MRI for evaluation of ligamentous knee injuries.

Material: This research was performed in 100 subjects (63 malesand37 females), aged between 12 and 73 years.

Results: The findings obtained showed that medial meniscal tears/degeneration (64 \%) followed by anterior cruciate ligament tear $(49 \%)$ were the most frequently found pathology of all subjects.

Conclusion: Magnetic resonance imaging has high sensitivity, precision and accuracy in the identification of posterior cruciate ligament and full anterior cruciate ligament tears; however, it has no adequate sensitivity in the detection of partial anterior cruciate tears.

Key Words: Magnetic resonance imaging (MRI), Anterior cruciate ligament (ACL), Posterior cruciate ligament (PCL)

\section{INTRODUCTION}

Magnetic resonance imaging has been useful in the identification of subjects, preoperative preparation, diagnosis, and better contact with the patient-doctor. ${ }^{1}$ The decline in the cost of MRI knee studies has also helped the orthopaedic community embrace them as a non-invasive alternative for arthrography and non-therapeutic arthroscopy.,3 The anatomic and pathologic interpretation of the soft tissue, ligaments, fibrocartilage and articular cartilage with MRI is superior to that seen with computed tomography (CT). ${ }^{4,5,6}$ Fast spin-echo imaging, used in combination with MR fat suppression technique, has increased MR 's sensitivity and precision to detect injuries to the articular cartilage. Besides, three-dimensional (3D) volume techniques have shown MR imaging 's flexibility in measuring meniscal tears. These can be used to reformat pictures of orthogonal and non-orthogonal planes with meniscal tears.

Aims and Objectives: Evaluation of ligamentous injuries of the knee on MRI

\section{MATERIAL AND METHODS}

Selection criteria: Subjects reporting knee injury history and consenting to report. Some those can comply with the MRI test, e.g. the willingness to lie immobile during the testing process.

Exclusion criteria: Subjects with cardiac pacemakers, metallic implants in the body, foreign body in the eye or with claustrophobia.

MRI scanner: MRI was performed with a PHILIPS ACHIEVA 1.5 T MR Scanner. A dedicated knee coil (FLEX M) was used.

Patient positioning: The MRI examination was conducted after ruling out the presence of any metallic implants or prosthesis in all the subjects. The patient was placed in a supine position with the knee in a closely coupled extremity coil. The knee was externally rotated $15-20^{\circ}$, to facilitate the visualization of ACL completely on sagittal images as it realigns the ACL parallel with the sagittal imaging plane. The knee

\section{Corresponding Author:}

Dr. Shirish V Vaidya, DMRD, DNB, Assistant Professor, Department of Radiodiagnosis, JNMC, Sawangi. Email: drshirish283@gmail.com

ISSN: 2231-2196 (Print) ISSN: 0975-5241 (Online)

Received: 12.05 .2020

Revised: 21.06 .2020

Accepted: 09.07.2020

Published: 22.07 .2020 
was flexed slightly $5-10^{\circ}$, to increase the accuracy of assessing the patella-femoral compartment and patellar alignment.

Imaging protocol: Standard surface phased array (FLEX M) coil was used for the identification of knee injury. In subsequent sagittal and coronal plane photos, an axial acquisition by patella-femoral joint was used as an initial localiser. The coronal plane tests the menisci collateral ligaments and body in an ideal manner. The sagittal plane exposes particularly the suprapatellar pouch, the cruciate ligaments, menisci and synovial anatomy. Through the incorporation of all three planes the bones, muscles, tendons, neurovascular structures have been thoroughly assessed.

\section{RESULTS}

In this present study of 100 subjects, 63 were men and 37 women. The youngest patient in the study was of $12 \mathrm{yrs}$, while the oldest patient was of 73 years. Most of the subjects were in the age group of 21- $50 \mathrm{yrs}$ with those in the age group of 41-50 yrs. being highest. Out of 100 subjects, 52 had derangements of the right knee while 48 had left-sided derangements. Out of 100 subjects in the study, 49 cases showed ACL tears and 9 subjects showed PCL tears.

Table 1: Distribution of Knee Pathologies

\begin{tabular}{lll} 
Sr. No & Pathology & No. of Subjects \\
1 & Medial Meniscal Tears & 64 \\
2 & Lateral Meniscal Tears & 31 \\
3 & Anterior Cruciate Ligament Tears & 49 \\
4 & Posterior Cruciate Ligament Tears & 9 \\
5 & Medial Collateral Ligament Tears & 5 \\
6 & Lateral Collateral Ligament Tears & 2 \\
7 & $\begin{array}{l}\text { Patellar Subluxations \&/or Patellar } \\
\text { Retinaculum Tears }\end{array}$ & 5 \\
8 & Popliteal Cysts & 22 \\
9 & Osteochondral Fractures & 12 \\
10 & Marrow Contusions At Condyles & 29 \\
\hline
\end{tabular}

\section{A. Anterior cruciate ligament (ACL) tears:}

Out of 49 subjects of ACL tears, 20 subjects (40.8\%) had full-thickness tears while 29 subjects $(59.2 \%)$ had partial thickness tear. On MRI, 29 subjects (59.2\%) had mid substance tears, 13 subjects $(26.5 \%)$ had tears at the femoral attachment and $7(14.3 \%)$ at the tibial attachment were detected.
Table 2: Location of ACL Tear

\begin{tabular}{lcc} 
ACL Tear & Number & Percentage \\
Midsubstance & 29 & $59.2 \%$ \\
Femoral Attachment & 13 & $26.5 \%$ \\
Tibial Attachment & 7 & $14.3 \%$ \\
\hline
\end{tabular}

Associated injuries with ACL: Out Of the 49 cases of ACL tears, 42 have been related to Meniscal Tears. Of these, 22 were associated with medial meniscal tears and 20 cases of lateral meniscal tears were associated. Medial meniscal tears were thus associated with ACL tears more frequently than others. In 22 (44.8 per cent) cases of an ACL tear, Marrow contusions and Bone Edema of the femoral condyle and tibial plateau were seen. In combination with ACL, chondral and osseous fractures in both medial and lateral compartments were also noted for 4 ( 8 per cent) cases. Collateral Ligament Tears accounted for ACL injuries in 4(8\%) situations. Tibial Spine Avulsion was noted in 1(2\%) case of an ACL tear. In our study, meniscal tears with marrow oedema and contusions off emoral and tibial condyles were most commonly associated with ACL tears.

\section{Table 3: Distribution of Associated Injuries with ACL} Tear

\begin{tabular}{llcc}
$\begin{array}{l}\text { Sr. } \\
\text { No. }\end{array}$ & ACL Tear Associated Injuries & Number & Percentage \\
1 & Meniscal Tears & 42 & $85.7 \%$ \\
2 & $\begin{array}{l}\text { Marrow ContusionsandBone } \\
\text { Edema of Femoral Condyle- } \\
\text { sandTibial Plateau }\end{array}$ & 22 & $44.8 \%$ \\
3 & $\begin{array}{l}\text { Fractures Of Femoral Condyles } \\
\text { \&/or Tibial Plateau }\end{array}$ & 4 & $8 \%$ \\
4 & $\begin{array}{l}\text { Collateral Ligament Tears } \\
5\end{array}$ & 4 & $8 \%$ \\
\hline
\end{tabular}

\section{B. Posterior cruciate ligament tears:}

pCL tears amounted for a small number of cases $9(9 \%)$ out of 100 subjects. All 9 subjects had partial-thickness tears along with 5 subjects having low-grade partial-thickness tears while 4 subjects having high-grade partial-thickness tears. Strain in PCL was found in another 9 subjects.

Associated injuries with PCL: Out of 9 cases of PCL tears, $3(33.33 \%)$ were associated with ACL tears. Meniscal injuries were associated with 2 cases $(22.22 \%)$ of PCL tears. Collateral ligament tears were associated with 2 cases $(22.22 \%)$ of PCL tears. Out of 9 patients of PCL tear, 1(11.11\%) pt. also had an avulsion fracture of the tibial plateau. Bone Contusion existed in 1 (11.11\%) of the case of PCL injuries. 
Table 4: Distribution of Associated Injuries with PCL Tear

\begin{tabular}{llcc} 
Sr & PCL Tear associated & Number & Percentage \\
No. & Injuries & 3 & $33.33 \%$ \\
1 & ACL Tears & 2 & $22.22 \%$ \\
2 & Meniscal Tears & 2 & $22.22 \%$ \\
3 & Collateral Ligament Tears & 1 & $11.11 \%$ \\
4 & Avulsion Tear off Tibial & 1 & \\
& Plateau & & $11.11 \%$ \\
\hline
\end{tabular}

scles, tendons, neurovascular structures have been thoroughly assessed.

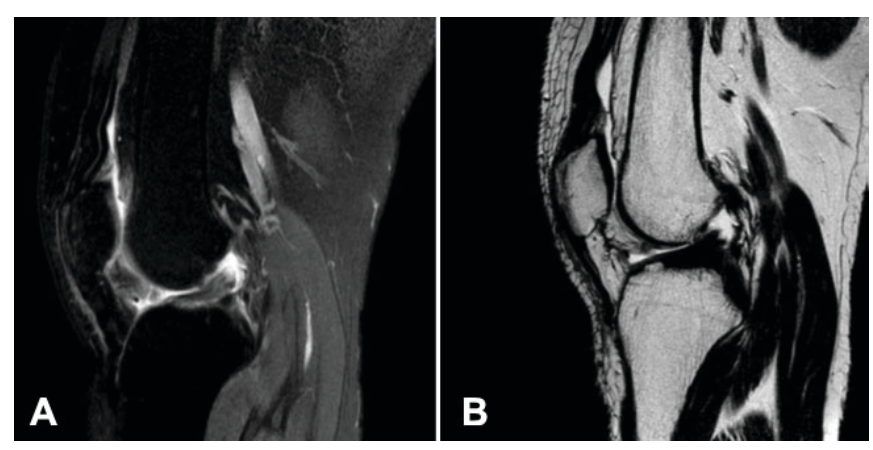

Figure 1 and 2: Sagittal PD FS(A) and T2W(B) images showing bulky $A C L$ with hyperintense signal and loss of Continuity s/o Acute ACL tear.

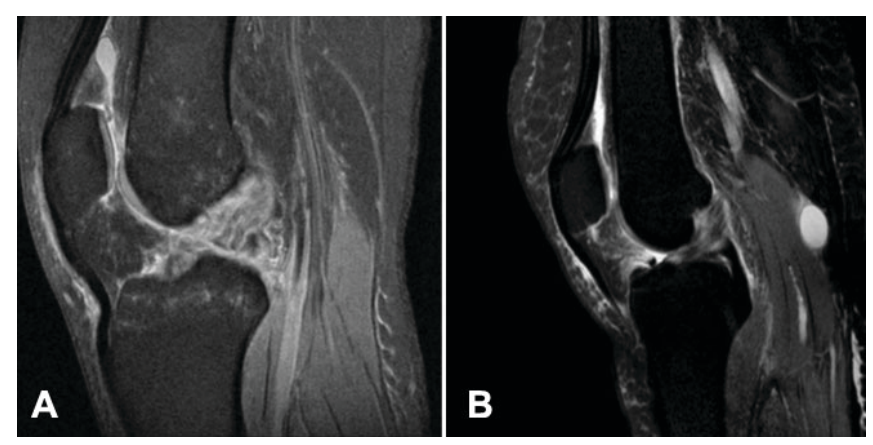

Figure 3: Sagittal PD FS images showing bulky ACL with hyperintense signal and loss of continuity in its mid-substance s/o complete ACL tear (A) \& (B) partial ACL tear showing hyperintense signal in $A C L$ on PD FS and laxity of the ligament on arthroscopy.

\section{DISCUSSION}

In our analysis we found that it was best to position the knee with $5-10^{\circ}$ flexionand $15-20^{\circ}$ external rotation. When ACL has been seen incompletely replicate oblique images have been obtained. T2WI and PDW FS images were preferred, as acute lesions were interpreted as high signal strength with high precision.

Anterior cruciate ligament tears: In our study Anterior cruciate ligament (ACL) tears were more common than posterior cruciate ligament (PCL). Lakhar et al. ${ }^{1}$ in their study on 173 subjects also reported ACL tear $(45.08 \%)$ to be more common than PCL tear(5.78\%). The most common tear location was at mid-substance. Lakhar et al. ${ }^{7}$ in their study reported mid substance tear as the most common type. Another study done by Berquist et al. ${ }^{8}$ showed a similar result.

Associated injuries with ACL: Meniscal tears were the most common finding associated with ACL tear in our research. 42 (85.7 per cent) of the 49 cases of ACL tears were associated with meniscal tears. Of those 42 cases of meniscal tears, 22 subjects suffered medial meniscal tears while 20 subjects had lateral meniscal tears. In their research, McDaniel et al. ${ }^{9}$ recorded that 85 to $91 \%$ of chronic ACL-deficient knees are associated with meniscal tears. In 22 (44.8\%) cases of ACL tear, Marrow contusions and bone oedema of the lateral femoral condyle and lateral tibial plateau were seen. Murphy et al. ${ }^{10}$ considered subchondral bone impactions posterolateral tibial plateau (94\%) and lateral femoral condyle ( $91 \%)$ to be relatively common indicators of an acute ACL tear. Fractures in both the medial and lateral compartments were also reported for $4(22.22 \%)$ cases in connection with ACL. Indelicato et al. ${ }^{11}$ in their study found that erosions and chondral fractures in both medial and lateral compartments were associated with ACL tears but in 23 per cent in acuteand54 per cent of chronic injuries, they observed these chondral fractures.

In our analysis, the triad of damage to the ACL by the classic O'Donoghue, MCL and medial meniscus was less severe in just $1(2.77 \%)$ case. In any case, ACL tear was not seen in Segond's fracture. Tibial spine avulsion was noted in ACL tear case 1(2.77\%). Kezdi-Rogus et al. ${ }^{12}$ found that Segond's fracture is associated with ACL rupture in $75 \%$ to $100 \%$ of cases and tibial spine avulsion is a rare but common finding for ACL injury. They also claimed that distal ACL injuries are often associated with avulsion injuries due to the comparatively stronger distal ACL fibres than adjacent tissue.

Posterior cruciate ligament tears: PCL tears accounted for 9(9 \%) of small cases. D S Shetty et al. ${ }^{13}$ observed PCL tears in only a small percentage of subjects in their sample of 115 subjects ( $4.34 \%$ )and the symptoms were hyperintensity in 3 subjects and discontinuity in 2 subjects. In their analysis, Sonnin et al. ${ }^{14}$ found a $2-23 \%$ occurrence as PCL injury. ACL tears 49 (49 \%) were much more common in our sample of 100 subjects than the PCL tears 9 (9\%). Chernye et al. ${ }^{15}$ reported that PCL is twice as strong as ACL, with a wider cross-sectional area and higher tensile strength resulting in lower PCL rupture incidence. 
Associated injuries with PCL: Out of 9 cases of PCL tears, $3(33.33 \%)$ were associated with ACL tears. The meniscal tear was seen to coexist with PCL tear in $2(22.22 \%)$ case. Collateral ligament tears accounted for $2(22.22 \%)$ cases in PCL injuries. Avulsion tear-off of tibial plateau accounted for $1(11.11 \%)$ cases. Bone contusion existed in $1(11.11 \%)$ case in PCL injuries. Niitsu et al. ${ }^{16}$ found $12(30.7 \%)$ subjects of isolated PCL tear among 39 subjects with PCL tears. The remaining 27 subjects showed evidence of other coexistent knee injuries, such as meniscal tears and ligamentous injuries. Of coexistent knee injuries, meniscal tears (18 subjects, $46.2 \%)$ were most common. 4 (10.3\%) subjects had avulsion tear-off of the tibial plateau.

\section{CONCLUSION}

The primary signs of ACL tear, including discontinuity, nonvisualization and irregular increased signal strength, were adequately established on FSE T2W and PDW FS and midsubstance was the most common tear position for the anterior cruciate ligament. Often noted were secondary symptoms, including bone contusions of the lateral femoral condyle and lateral tibia, anterior tibial translation, lateral meniscus rear horn uncovering, and PCL buckling. As in other research, FSE T2 and PD FS sequences are most prone to the spectrum of menisci land cruciate ligament tears and the related injuries like osteochondral fractures, while SE T1 sequence was useful to correlate pathology other than ligament tears. PD FS sequences were useful to evaluate associated bone contusions. The high degree of precision in MRI evaluation in various planes and positioning of the knee in $15-20^{\circ}$ of external rotation and $5-10^{\circ}$ of flexion helped to delineate the location and the full range of lesions. Magnetic resonance imaging has high sensitivity, precision, and accuracy in the diagnosis of meniscal, posterior cruciate ligament, and full anterior cruciate ligament tears; however, there is inadequate sensitivity to detect partial anterior cruciate tears.

Acknowledgement: Authors acknowledge the immense help received from the scholars whose articles are cited and included in references of this manuscript. The authors are also grateful to authors / editors / publishers of all those articles, journals and books from where the literature for this article has been reviewed and discussed.

Ethical clearance-Taken from the institutional ethics committee.

\section{Source of funding- Self.}

\section{Conflict of Interest- Nil.}

\section{REFERENCES}

1. Kean DM, Worthington BS, Preston BJ. Nuclear MRI of knee: examples of normal anatomy and pathology. Br J Radiol 1983; 56: $355-361$.

2. Nikken JJ, Oei EHG, Ginai AZ, et al. Acute peripheral joint injury: cost and effectiveness of low-field-strength MR imaging-results of r\&omized controlled trail. Radiology 2005; 236:958-967.

3. Nagrale N, Barmate N. Age determination by radiological assessment of epiphyseal union of bones at knee joint in chhattisgarh region. Journal of South India Medicolegal Association. 2019; 11 (1): 30-35.

4. Moon KL, Genant HK, Helms CA, Chafetz NI, Crooks LE, Kaufman L. Musculoskeletal applications of nuclear MR. Radiology 1983; 147: 161-171.

5. Mahato R, Panchal D, Vyas N. Exercise interventions in Knee Osteoarthritis in Aging adults: A Systematic Review of Randomized Clinical Trials International Journal of Current Research and Review. 2011; 23(11) 01-05.

6. Kumar P, Kumar A, Venkatesh D. Healthy Gait: Review of Anatomy and Physiology of Knee Joint International Journal of Current Research and Review. 2005;12(6): 01-08

7. B N Lakhkar, K V Rajagopal, P Rai. MR Imaging of Knee with Arthroscopic Correlation in Twisting Injuries. Ind J Radiol Imag. 2004; 14:1:33-40.

8. Berquist TH. Magnetic resonance techniques in musculoskeletal diseases. Rheum Clin North Am 1991; 17: 599-615.

9. McDaniel WJ. Untreated ruptures of the anterior cruciate ligament. J Bone Joint Surg [Am] 1980; 62:696.

10. Murphy BJ, Smith RL, et al. Bone signal abnormalities in the posterolateral tibia and lateral femoral condyle in complete tears of the anterior cruciate ligament: a specific sign? Radiology 1992; 182:221.

11. Indelicato PA, et al. A perspective of lesions associated with ACL insufficiency of the knee. A review of 100 cases. Clin Orthop 1985; 198:77.

12. Kezdi-Rogus PC, Lomasney LM. Plain film manifestations of ACL injury. Orthopaedics 1994; 17:969.

13. Shetty D, Lakhkar B, Krishna G. Magnetic Resonance Imaging in Pathologic Conditions of Knee. Ind J Radiol Imag 2002 12:3:375-381.

14. Sonin AH, Fitzgerald SW, Friedman H, Hoff FL, Hendrix RW, Rogers LF. PCL injury: MR imaging diagnosis and pattern of injury. Radiology 1994; 190: 455-458.

15. Chernye S. Disorders of the knee. In: Deer, et al, eds. Principles of orthopaedic practice, vol 2. New York: McGraw-Hill, 1989:1283.

16. Takahashi N, Niitsu M et al. MR imaging of posterior cruciate ligament injuries. Nippon Igaku Hoshasen Gakkai Zasshi. 2001; 61(8):421-6. 